\title{
Do Insurers Compete on the Federal Health Insurance
}

\section{Exchange? [version 1; peer review: 2 approved with}

\section{reservations]}

Jesse N. Cohen ${ }^{1}$, Alexander Coppock², Arnab K. Ghosh¹, Benjamin P. Geisler ${ }^{1}$

${ }^{1}$ New York University, New York, NY 10016, USA

2Department of Political Science, Columbia University, New York, NY 10025, USA

V1 First published: 27 Jan 2015, 4:25

https://doi.org/10.12688/f1000research.6039.1

Latest published: 27 Jan 2015, 4:25

https://doi.org/10.12688/f1000research.6039.1

\section{Abstract}

Background: On the U.S. Federal Health Insurance Exchange

established by the Affordable Care Act, states with fewer insurers have higher insurance premiums than states with more insurers. This expected feature of a competitive market has not been studied within states, however. We tested the hypothesis that insurance premiums decrease in more competitive geographic rating areas within states in the U.S.A.

Methodology/principle findings: This cross-sectional study utilized publicly available premiums from the Federal Health Insurance Exchange website, www.healthcare.gov. Univariate and multivariate analyses were used to model premiums based on the number of insurers in geographic rating areas. The relationship between premiums and the number of insurers competing in a geographic rating area was also calculated for each unique insurance plan offered on the exchange. The data set and statistical code used for this research is linked in the publication. We found that there was an unexpected, marginally positive relationship between average monthly premiums and the number of insurers in a geographic rating area ( $\$ 5.71$ in monthly premiums per additional insurer, $p<0.001)$. We also found that identical plans tend to be offered with marginally higher premiums in rating areas with more insurers $(+\$ 3.18$ in monthly premiums per additional insurer, $\mathrm{p}=0.002$ ), contrary to the relationship we expected from a competitive marketplace. The principle limitation of the study is that this unexpected relationship, which suggests a lack of competitiveness of this early market, could be due to unobserved confounding factors that influence pricing in more competitive rating areas.

Conclusion: On the Federal Health Insurance Exchange, the price of insurance is higher in more competitive rating areas within states. This may be explained by lack of competition in this early stage market.

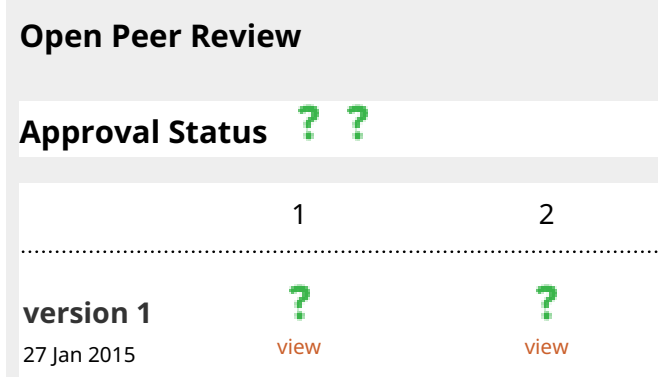

1. Cynthia Cox, Kaiser Family Foundation, Menlo Park, USA

2. Jon Gabel, University of Chicago, Bethesda, USA

Any reports and responses or comments on the article can be found at the end of the article. 
Keywords

Health, Insurance, Exchanges, Patient, Protection, and, Affordable, Care, Act, Economic, Competition

Corresponding author: Jesse N. Cohen (jesse.cohen@nyumc.org)

Competing interests: No competing interests were disclosed.

Grant information: The author(s) declared that no grants were involved in supporting this work.

Copyright: @ 2015 Cohen JN et al. This is an open access article distributed under the terms of the Creative Commons Attribution License, which permits unrestricted use, distribution, and reproduction in any medium, provided the original work is properly cited. Data associated with the article are available under the terms of the Creative Commons Zero "No rights reserved" data waiver (CC0 1.0 Public domain dedication).

How to cite this article: Cohen JN, Coppock A, Ghosh AK and Geisler BP. Do Insurers Compete on the Federal Health Insurance Exchange? [version 1; peer review: 2 approved with reservations] F1000Research 2015, 4:25 https://doi.org/10.12688/f1000research.6039.1

First published: 27 Jan 2015, 4:25 https://doi.org/10.12688/f1000research.6039.1 


\section{Introduction}

Lack of competition in the U.S. health insurance market may contribute to higher prices for consumers, lower reimbursements for physicians, and greater profits for insurance companies ${ }^{1}$. In recent years, competition between insurers has been decreasing due to conglomeration of large insurers ${ }^{2}$. Through the Affordable Care Act (ACA), Congress attempted to improve the competitiveness of the insurance marketplace for individual buyers with the creation of online exchanges that facilitated comparison of plans and prices by consumers ${ }^{3}$. Nevertheless, consumer choice is still restricted by geography; not all plans are offered in all places. Most locations in the U.S. have few offerings, and identical plans are offered at different prices in different areas. As a result, many consumers still face a largely noncompetitive insurance market ${ }^{4-6}$.

On the exchanges established by the ACA, consumers must purchase plans from their own "rating areas". The definition of a rating area changes considerably from state to state, but rating areas are typically a collection of similar counties within a state. They can also represent metropolitan statistical areas, and, in a few cases, the entire state. Prices for identical plans can vary across rating areas, but cannot vary within them. About half of U.S. counties on the exchanges belong to rating areas with only one or two insurers. Though states with fewer insurers have higher insurance prices on average $^{7}$, this inverse relationship between price and the number of insurers per area has not been described at the level of withinstate rating areas, which are the smallest geographic units of price variation on the federal health insurance exchange. Furthermore, no previous studies have tracked how insurers change the prices of identical plans that are offered in variably competitive rating areas. Since the negative correlation between the degree of competition and average state insurance prices could be due to confounding from interstate variations in cost of care, healthcare utilization ${ }^{8}$, or market share of healthcare provider organizations, it is worthwhile to investigate the relationship with finer granularity within states.

This article examines the hypotheses that average prices of insurance plans on the federal exchange decrease in more competitive rating areas within states, and that identical insurance plans are offered at lower prices in more competitive rating areas within states.

\section{Methods}

\section{Data source}

Data were obtained from the Federal Health Insurance Exchange website, www.healthcare.gov, on October $17^{\text {th }} 2013$. The dataset contained all insurance plan offerings for 34 of the 36 states participating in the federal exchange. Idaho and New Mexico were not in the database. The operator of the federal exchange, the Centers for Medicare \& Medicaid Services, listed premiums for different rating areas.

\section{Statistical analysis}

We defined a unique insurance plan as an offering by an insurance company with a unique plan name, metal tier (bronze, silver, etc.), network type (e.g., health maintenance organizations), and U.S. state. We excluded plans that had no monthly premiums listed. For precision of comparison, only family plans (two children and two forty year-old adults) were studied. Premiums for all other customer arrangements (single individuals for example) were related to the family plan premium based on a pre-set multiplier used by all insurers. The first analysis estimated the relationship between family plan premiums and the number of insurers per rating area using Ordinary Least Squares (OLS).

The second analysis estimated a varying-intercept, varying-slope model of family plan premiums and the number of insurers per rating area ${ }^{9}$. This multivariate linear regression model is equivalent to estimating separate regressions of price on the numbers of insurers per rating area for each unique insurance plan. This model is appropriate as there is considerable heterogeneity between plans in the relationship being studied (price on the number of insurers per rating area). The varying-intercept, varying-slope model effectively restricts the analysis to insurance plans that are offered in multiple rating areas with differing numbers of insurers, however. See Figure 1 and Figure 2 for a conceptual outline of the difference between our two models.

Figure 3 is a histogram of the slopes of the varying-intercept, varying-slope model, where each slope equals the change in premium associated with an increase of one insurer per rating area. The average slope was calculated and compared to zero using a t-test.

All statistical analyses were performed with $\mathrm{R}$ statistical package ( $\mathrm{R}$ Project for Statistical Computing, www.r-project.org). The statistical code in $\mathrm{R}$ for our research is available at http://dx.doi.org/10.5281/ zenodo.14122.

\section{Premiums vs Number of Insurers in Rating Area}

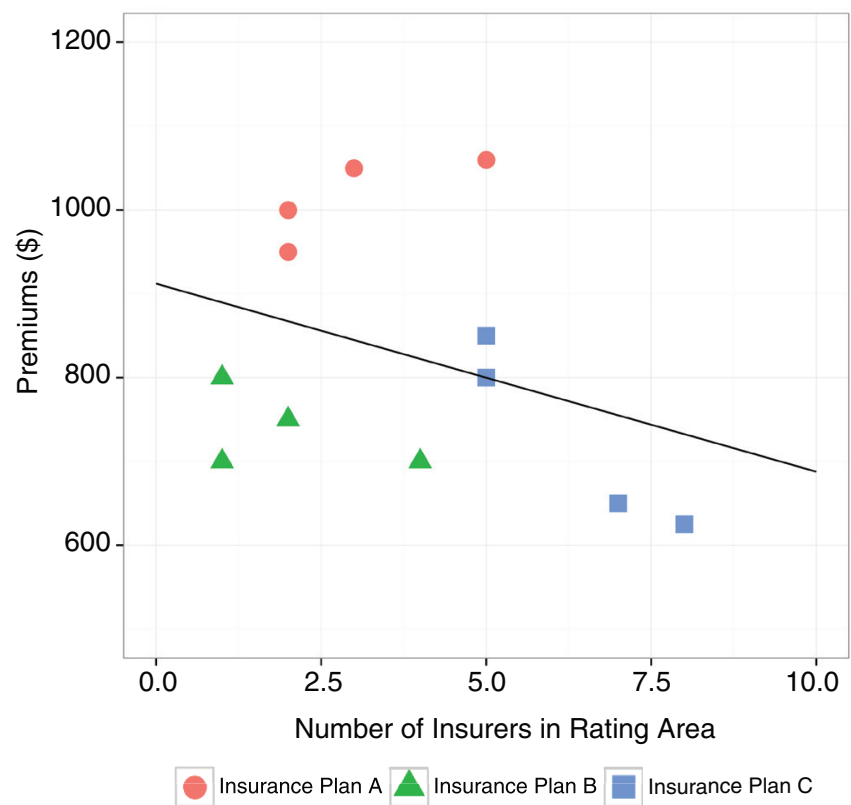

Figure 1. A simple linear regression (Ordinary Least Squares) is plotted comparing premiums on the number of insurers per rating area. Premium $=\beta_{0}+\beta_{1}$ (Number of insurers). This model cannot capture the behavior of individual plans $(A-C)$ in different rating areas, however. 
Premiums vs Number of Insurers in Rating Area

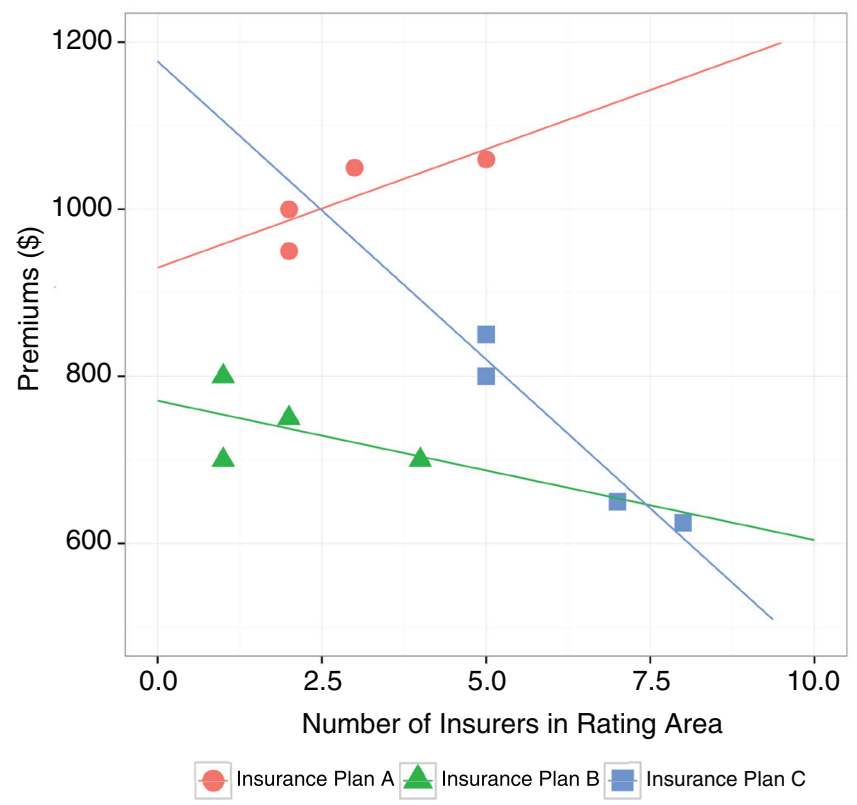

Figure 2. A varying-intercept, varying-slope model is plotted capturing the different behavior of insurance plans $\mathbf{A}-\mathrm{C}$. Premium $=\beta_{0}+\beta_{1}$ (Number of insurers) $+\beta_{2}$ (Insurance Plan $\left.A\right)+\beta_{3}$ (Insurance Plan $B)+\beta_{4}$ (Insurance Plan $A^{*}$ Number of insurers) $+\beta_{5}$ (Insurance Plan $B^{*}$ Number of insurers). Where Insurance Plan $A=0,1$ and Insurance Plan $B=0,1$, and the base case is insurance plan $C$. Slope for Insurance Plan A, for example, is $\beta_{1}+\beta_{4}$. Multiple regression lines are created with unique slopes and intercepts for each insurance plan. These slopes can be summarized in a histogram, as was done in our study.

\section{Distribution of Slopes}

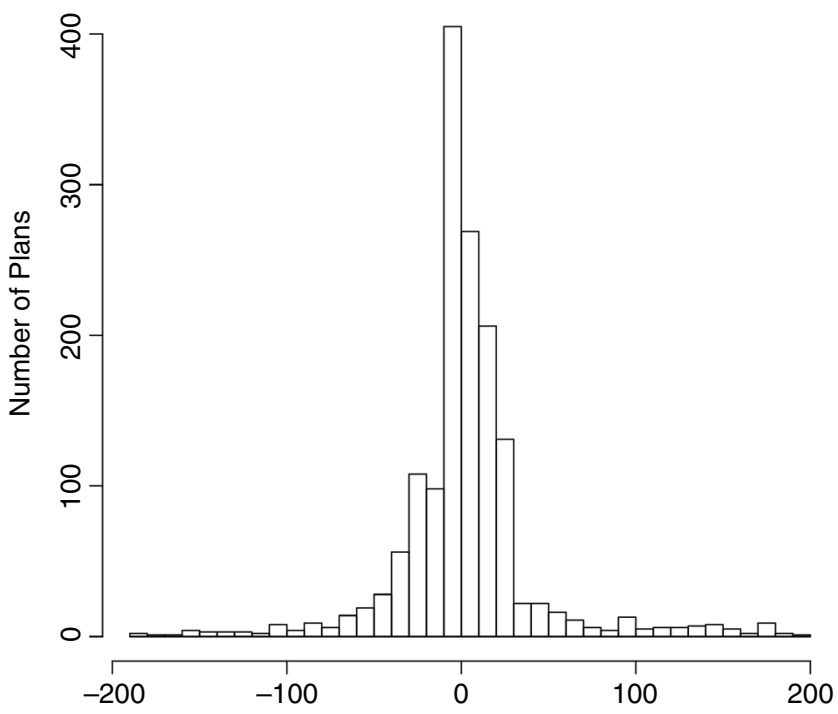

Change of Premium (\$) per Additional Insurer in Rating Area, by Plan

Figure 3. Distribution of Slopes of Premiums versus the Number of Insurers per Rating Area (US dollars per additional insurer per rating area), for each Insurance Plan.

\section{Results}

The Federal Health Insurance Exchange listed 2,276 unique plans offered by 139 insurers, in 34 states with 395 rating areas. The 2,276 unique plans were offered with different premiums based on the rating area. In total, there were 16,887 offerings across rating areas.

The number of rating areas per state varied from one (New Jersey, New Hampshire, and Delaware) to sixty-seven (Florida). See Figure 4 for the distribution of rating areas per state. The number of insurers per rating area varied from one to ten. $13 \%$ of rating areas had one insurer, $40 \%$ had two insurers (Figure 5).

Insurance plans frequently changed prices across rating areas within a state. The average difference between the maximum and minimum prices, the range, for particular insurance plans across rating areas was $\$ 120$. The largest range in the dataset was $\$ 1,459$. Nearly all other plans ranged by less than $\$ 500$ across rating areas, however.

We estimated the average relationship between family plan premiums and the number of insurers in a rating area by Ordinary Least Squares. The estimated slope was $+\$ 5.71$ for each additional insurer $(\mathrm{p}<0.001)$. This simple model contradicts the hypothesized relationship in which increased competition decreased prices, but the model had an $\mathrm{R}^{2}$ of only 0.0007 .

To more closely model how specific plans change prices in variably competitive rating areas, we estimated the relationship between competition and price for each unique plan separately. This was accomplished by a varying intercept, varying slope model, estimated

\section{Distribution of Rating Areas per State}

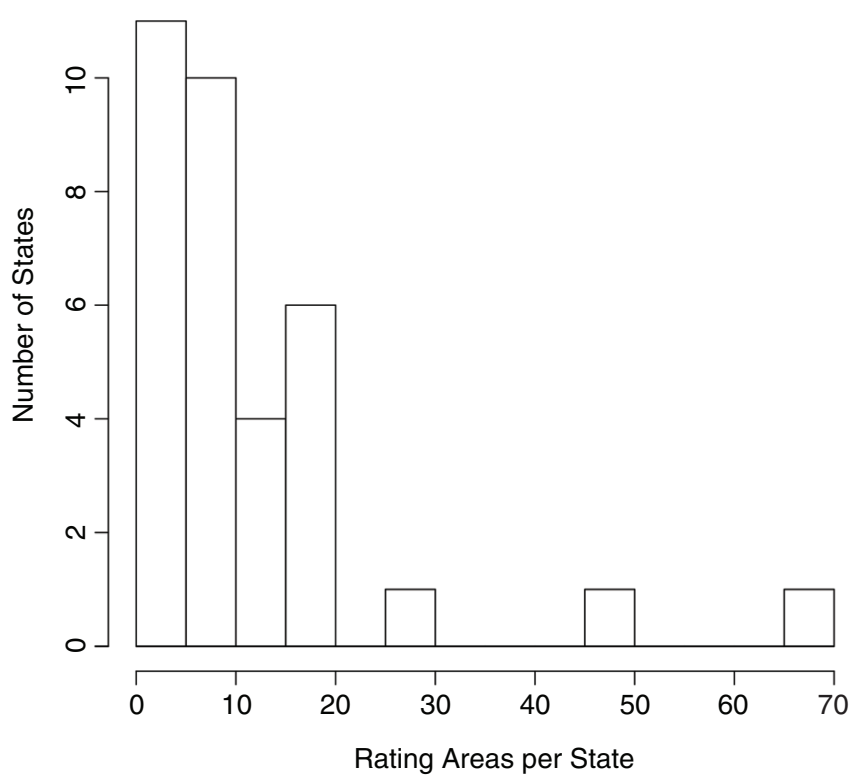

Figure 4. Distribution of Rating Areas per State on the Federal Health Insurance Exchange. 


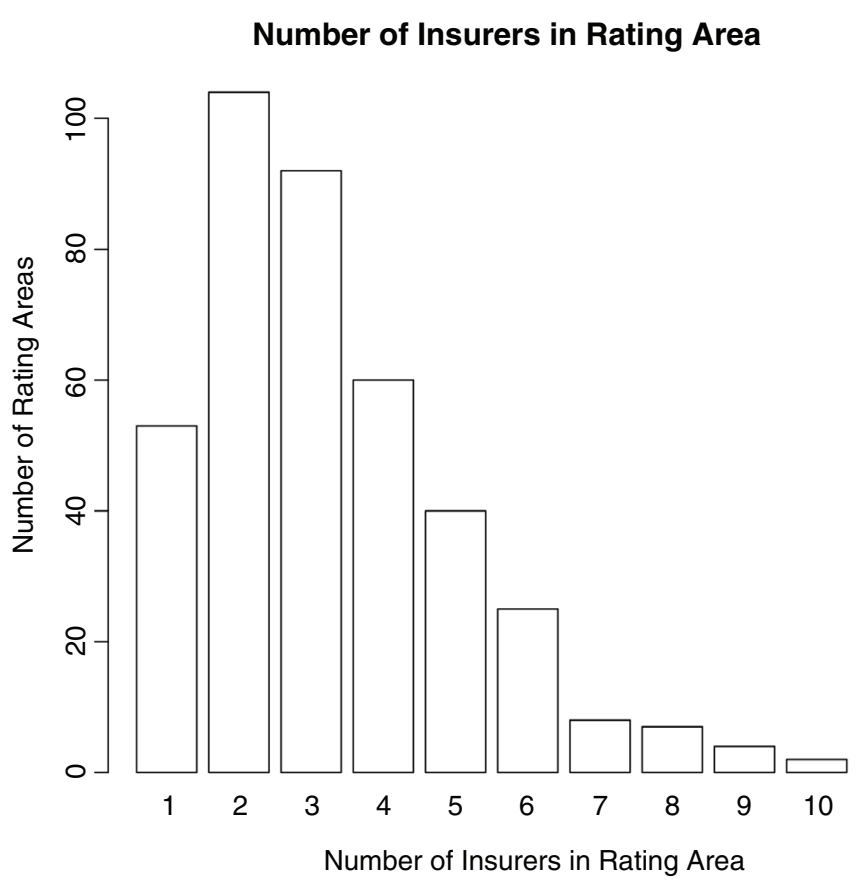

Figure 5. Distribution of the Number of Insurers Offering Plans in a Rating Area on the Federal Health Insurance Exchange.

by Ordinary Least Squares. We were able to estimate slopes for 1,512 of the 2,276 unique plans; the remainder were only offered in rating areas with equal numbers of insurers. The average slope for this model was $+\$ 3.18$ for each additional insurer per rating area. This average could be distinguished from zero at $p=0.002$. The $\mathrm{R}^{2}$ of this more complicated model was 0.97 , indicating much better model fit. The distribution of slopes from this model are presented in a histogram in Figure 3, which provides a sense of how varied the relationship between competition and price was.

\section{Discussion}

Our hypotheses were that on the Federal Health Insurance Exchange, rating areas with more competitors would have lower average premiums than rating areas with fewer competitors, and that identical plans would be offered at lower prices in ratings areas with more competitors, presumably representing the effect of price competition. We found no evidence that increased numbers of insurers correlated with lower premiums, either for plans on average, or for plans tracked individually, however. We found instead that premiums increased marginally in rating areas with more competitors. This finding contradicts the previously documented negative correlation between premiums and the number of insurers as measured at the state level ${ }^{7}$.

There are multiple potential explanations for the contradiction of our hypothesis. Rating areas with more insurers may have higher medical or administrative costs, leading to higher premiums. Rating areas with more insurers may also be wealthier, leading to higher premiums through price discrimination. In contrast, if these areas are less wealthy, more consumers would be eligible for financial subsidization, possibly allowing higher prices to be offset by subsidies. In addition to the above factors, marginally higher prices in more competitive rating areas may simply reflect an absence of competition in this early market with an unknown customer base.

Effects of competition in this online market may yet be seen as the "risk pool" becomes better understood, and pricing approaches market equilibrium. Alternatively, we may not see substantial price competition between insurers on this new market, as insurer price competition has only been documented in a small collection of studies, mostly limited to health maintenance organizations ${ }^{10}$.

Our study had strengths in comparison to the previous literature. We examined the relationship between price and competition at the level of within-state rating areas, which yields a fine grained analysis compared to measuring the relationship between states. We may have reduced some geographic confounding using this method. We also tracked and summarized the pricing behavior of individual plans across areas with varying degrees of competition, which is a novel measurement of competitiveness.

Our study was also subject to limitations. First, we did not capture the prices of plans that are offered off of the federal exchange, which is a potential underlying component of the competitive landscape in each rating area. Second, we reported on initial price offerings, not actual sales from 2014. Sales information would allow a calculation of the Herfindahl-Hirschman Index (HHI), an established metric of market competitiveness, but this data is not yet publically available. Lastly, we could not correct for confounding by rating area within states. Any model that examines premium variation as a factor of local competition will be left with the limitation that rating areas with higher numbers of insurers may simply be more expensive based on an unmeasured factor, which would confound a negative relationship expected in a competitive market. In short, there may be unobserved reasons that plans in rating area with more competition command higher premiums.

In conclusion, though an intention of the Federal Health Insurance Exchange was to foster competition between insurers and therefore lower insurance prices, we observed instead marginally higher prices in areas with more competition. This finding is important for policy makers, as the power of competition to lower health insurance prices is a theoretical underpinning of the Affordable Care Act.

Dataset 1. Healthcare.gov Insurance Exchange Prices for 2014 http://dx.doi.org/10.5256/f1000research.6039.d42413

Publicly available database from healthcare.gov with the prices for exchange plans from 2014 and the rating areas where these plans are offered to consumers. 


\section{Data availability}

F1000Research: Dataset 1. Healthcare.gov Insurance Exchange Prices for 2014, 10.5256/f1000research.6039.d42413 ${ }^{11}$

Source code in R: http://dx.doi.org/10.5281/zenodo.14122 $2^{12}$

Author contributions

JC, AG, BG conceived the study. JC, AC carried out all statistical analysis. JC was the primary author of the manuscript. JC, AC, AG, BG provided critical editing.

\section{Competing interests}

No competing interests were disclosed.

Grant information

The author(s) declared that no grants were involved in supporting this work.

\section{Acknowledgments}

We acknowledge Mack Lipkin Jr., MD, and Kathleen Hanley, MD, for critical editing and invaluable mentorship.
1. American Medical Association. Competition in health insurance: A comprehensive Study of U.S. Markets. 2007 Update. American Medical Association, 2007. Reference Source

2. Robinson JC: Consolidation and the transformation of competition in health insurance. Health Aff (Millwood). 2004; 23(6): 11-24. PubMed Abstract | Publisher Full Text

3. Skopec L, Kronick R: Market Competition Works: Silver Premiums in the $\mathbf{2 0 1 4}$ Individual Market Are Substantially Lower than Expected. Office of the Assistant Secretary for Planning and Evaluation. Department of Health and Human Services. 2013. Reference Source

4. Abelson R, Thomas K, McGinthy JC: Health Care Law Fails to Lower Prices For Rural Areas. New York Times. 2013. Reference Source

5. Senger A: Lack of Competition in Obamacare's Exchanges: Over Half of U.S. Has Two or Fewer Carriers. The Heritage Foundation. Retrieved June 4, 2014. Reference Source

6. Cox CM, Rosa CG, Levitt L: Sizing Up Exchange Market Competition. The Henry J. Kaiser Family Foundation. Issue Brief. 2014.

Reference Source
7. Health Insurance Marketplace Premiums for 2014. Office of the Assistant Secretary for Planning and Evaluation. Department of Health and Human Services. $2013 ; 4$.

Reference Source

8. Gottlieb DJ, Zhou W, Song $Y$, et al: Prices don't drive regional Medicare spending variations. Health Aff (Millwood). 2010; 29(3); 537-43. PubMed Abstract | Publisher Full Text | Free Full Text

9. Gelman A, Jennifer H: Data Analysis Using Regression and Multilevel/ Hierarchical Models. 2007. Reference Source

10. Dicken JE: Private Health Insurance: Research on Competition in the Insurance Industry. United States Government Accountability Office. 2010; 1-13. Reference Source

11. Cohen JN, Coppock A, Ghosh A, et al.: Dataset 1. Healthcare.gov Insurance Exchange Prices for 2014. F1000Research. 2015 Data Source

12. Cohen JN, Coppock A, Ghosh A, et al.: Replication Code in $\mathbf{R}$ for "Do Insurers Compete on the Federal Heath Insurance Exchange. Zenodo. 2015. Data Source 


\title{
Open Peer Review
}

\section{Current Peer Review Status: ? ?}

\section{Version 1}

Reviewer Report 19 March 2015

https://doi.org/10.5256/f1000research.6465.r8034

(C) 2015 Gabel J. This is an open access peer review report distributed under the terms of the Creative Commons Attribution License, which permits unrestricted use, distribution, and reproduction in any medium, provided the original work is properly cited.

\author{
Jon Gabel \\ NORC, University of Chicago, Bethesda, MD, USA
}

\section{When Results Seem Implausible, It Is Wise to Take a Second Look}

Jesse Cohen and his colleagues present their analysis of the relationship between premiums on the exchange and the number of insurers in a market area, and conclude that premiums rise $\$ 5.71$ for each additional insurer on the exchange. Their analysis is based on data from 34 states on the Federally Facilitated Marketplaces (FFMs) in 2014. Cohen and his colleagues conclude that in the early stages, there is a lack of price competition on the exchanges among insurers.

There is a lengthy history in the health economics profession debating counter-intuitive findings. In the late 1970 s and 1980s, many economists, including myself, pointed to the higher physician fees in areas with more physicians per capita, and argued this was consistent with physicianinduced demand. Similarly, during the $70 \mathrm{~s}$ and $80 \mathrm{~s}$, there was wide acceptance of the proposition that if a hospital could add additional beds, the beds would be filled.

But times have changed, and the fee-for-service and indemnity insurance world of the 70s and $80 \mathrm{~s}$ is long gone. Activist employers and managed care have helped put many of the older controversies to rest, and a strategy of competition is now embraced by both parties. To build a price competitive Marketplaces, the Affordable Care Act borrowed from the playbook of conservative economists such as Alain Enthoven and Mark Pauly ${ }^{1,2}$. Subsidies are pegged to the second lowest silver plan, so that the cost of a higher cost plan is borne entirely by the purchasing household. Essential benefits, metal tiers based on actuarial values and transparency offered through state websites promote price sensitive buying.

Rather than illustrating a lack of competition among insurers, current evidence suggests that the exchanges are bringing price competition into the non-group market not witnessed in many years. Premiums cost 16 percent less than those predicted by the Congressional Office in $2014^{3}$. Sixty-four percent of 2014 Marketplace enrollment was for the lowest or second lowest cost plan on the metal tier in the rating area ${ }^{4}$. There was a 25 percent increase in the number of carriers in 2015 competing on the Marketplaces and in some states new entrants gained not just a plurality 
of enrollment, but a majority ${ }^{5}$. The number of plans offered rose by 25 percent. Some new entrants gaining the largest market share in 2014 went bankrupt or exited the market in 2014$2015^{6}$. This occurred in Iowa, Nebraska, and Minnesota for two co-op plans and a hospital-based plan.

Between 2014 and 2015 the average cost of Marketplace plans did not increase. Deductibles also remained essentially unchanged. Pricing of plans followed a regression toward the mean pattern, with low cost 2014 plans increasing and high cost plans reducing their premiums. So connecting the dots, it appears the Marketplaces were built to be and are price competitive ${ }^{5}$.

\section{Analysis of Cohen and Colleagues}

The authors conducted two sets of analyses. In the first, using ordinary least squares regression, they estimated the relationship between the number of insurers in a rating area and the average premium. In the second, they use a variable slope, variable intercept model which the authors describe as equivalent to estimate separate regression for each plan offered in multiple areas within a state. It is from these second analyses that the authors reach their conclusion that as the number of insurers within a market area increases, premiums likewise increase. I thought it was insightful that the authors examined premiums for the same plan in different market areas within a state.

Cohen and colleagues themselves point out that there may be intervening variables that explain these unexpected findings - that areas with more insurers have higher premiums. Large states have more insurers participating on the exchanges and small rural states may have but one insurer participating. Within a state, rural areas tend to have fewer insurers participating compared to urban and suburban areas. Medical expenses, particularly hospital expenses, are higher in urban and suburban areas. Physician practice expenses such as rent and labor are greater in urban/suburban areas. However, in some rural areas local hospitals have de facto monopolies, and in some of these areas such as southern rural Georgia, premiums are very high.

Before we accept the authors' conclusions, I suggest that they control for the many intervening variables. These include; (1) area per capita income (2) some measure of average hospital costs in the rating area (3) percent of the population that is uninsured in the rating area (4) some measure of "urbanness" (5) type of insurer (Blue Cross Blue Shield, major commercial carrier, co-op, provider-based, Medicaid base etc.

One other concern I have is that certain states may have undue weight. For example, in Florida, Governor Rick Scott and the Republican controlled legislature, to thwart the implementation of the $A C A$, divided the state into 58 regions. So Florida would have undue influence on findings. I suggest weighting each area by the uninsured population or total population.

In fairness to Cohen and his colleagues, the authors note that the results may reflect the early stages of competition on the Marketplaces. Now that 2015 data are available for FFS states, I invite the authors to pool two years of data and determine if there initial observations still hold, with a fully specified model.

\section{References}


1. Enthoven A, Kronick R: A consumer-choice health plan for the 1990s: Universal Health Insurance in a System Designed to Promote Quality and Economy (first of two parts). N EnglJ Med. 1989; 320: 29-37 Publisher Full Text

2. Pauly MV, Danzon $P$, Feldstein $\mathrm{P}$, Hoff J: A plan for 'responsible national health insurance'. Health Aff (Millwood).1991; 10 (1): 5-25 PubMed Abstract | Publisher Full Text

3. Luhby T: The Obamacare Premiums Will Cost Less than Predicted, according to Data Released Wednesday by the Obama administration.CNN Money. September 25, 2013. Reference Source 4. Health Plan Choice and Premiums in The 2015 Health Insurance Marketplace. ASPE Research Brief. January 8, 2015. Reference Source

5. Gabel JR, Whitmore H, Stromberg S, Green M, et al.: Analysis Finds No Nationwide Increase in Health Insurance Marketplace Premiums. The Commonwealth Fund. December 22, 2014. Reference Source

6. Mangan D: Obamacare Co-ops Try to Swim-Not Sink-As Red Ink Persists. CNBC. January 26, 2015. Reference Source

Competing Interests: No competing interests were disclosed.

\section{I confirm that I have read this submission and believe that I have an appropriate level of expertise to confirm that it is of an acceptable scientific standard, however I have significant reservations, as outlined above.}

Reviewer Report 16 February 2015

https://doi.org/10.5256/f1000research.6465.r7477

(c) 2015 Cox C. This is an open access peer review report distributed under the terms of the Creative Commons Attribution License, which permits unrestricted use, distribution, and reproduction in any medium, provided the original work is properly cited.

\section{Cynthia Cox}

Kaiser Family Foundation, Menlo Park, CA, USA

This study analyzes the relationship between Federally Facilitated Marketplace (FFM) premiums and the number of insurers participating in the region. The authors present a good overview of the dataset used, existing literature, and limitations in the availability of data (particularly the lack of plan-level signup data, which would allow for examination of market concentration).

The use of family premiums is appropriate, but as the authors note, age curves are the same in almost all FFE states, so single adult premiums would have yielded similar results (though the dollar amounts would be smaller). Rating regions are also the appropriate level of analysis. The analysis could be repeated with the second year of data (2015) as this has been publicly available for some time.

The study consists of two parts: 1) simple regression where average premium is the dependent variable and 2) a varying-intercept, varying-slope model of the relationship between unique plans' premiums and the number of insurers in the rating area. As I will describe in more detail below, the first analysis has significant flaws/limitations. I would suggest minor revisions and elaboration 
on the second analysis.

On the first analysis, my concern is that the dependent variable should not be the average premium in the rating area. Rather, the dependent variable should be the lowest and/or secondlowest cost premium by metal level in the rating area. This is for two reasons:

First, conceptually, exchange subsidies are structured such that insurers have an incentive to compete to offer the lowest-cost product within each metal level (or possibly the benchmark in the case of silver plans). We saw from 2014 HHS enrollment reports that the majority of consumers purchased one of the two lowest cost silver or bronze plans.

Second, in urban areas, where more insurers participate, a wider range of products are typically offered within each metal level, and insurers may also be more likely to offer higher-cost platinum coverage. A wide range of products may result in higher average premiums, even while insurers are competing to offer the lowest-cost product within a metal level.

The second analysis has potential to make a contribution to the literature and bears elaboration. One small methodological issue, though, is the use of plan names, rather than the plan ID standard component, to identify unique plans. Insurers may offer similar plans that are listed with the same marketing name in the dataset but in reality have slight variations. In some cases this is because one plan may have a narrower network (and therefore lower premium), and in other cases it may be that the insurer filled out the plan marketing name incompletely.

For example, FirstCare Health Plans in San Saba County Texas offers two gold HMO plans with marketing names of "FirstCare Health Plans" but the plan IDs differ (26539TX0140001 and 26539 TX0140002), and they have slightly different premiums ( $\$ 310.39$ and $\$ 305.89$, respectively, for a 40-year-old individual). From the dataset alone, we do not know whether this is simply an error in the marketing name or that the two plans are similar other than their networks, but in either case, they should be counted as two distinct plans. An alternative would be to use a combination of unique plan marketing names and unique premiums within the rating area to identify unique plans. To be clear, I doubt the use of plan IDs vs. plan names to identify unique plans would have a significant effect on the overall findings, but it would be a cleaner analysis.

Finally, I would like to see more elaboration on the second analysis. For example, I am interested in hearing more about the plans that are only offered in one rating area or that did not vary in price between rating areas. Are these plans lower cost, on average, relative to the insurers' other products in those areas? More elaboration on the excluded plans would be beneficial.

Competing Interests: No competing interests were disclosed.

I confirm that I have read this submission and believe that I have an appropriate level of expertise to confirm that it is of an acceptable scientific standard, however I have significant reservations, as outlined above. 
The benefits of publishing with F1000Research:

- Your article is published within days, with no editorial bias

- You can publish traditional articles, null/negative results, case reports, data notes and more

- The peer review process is transparent and collaborative

- Your article is indexed in PubMed after passing peer review

- Dedicated customer support at every stage

For pre-submission enquiries, contact research@f1000.com 